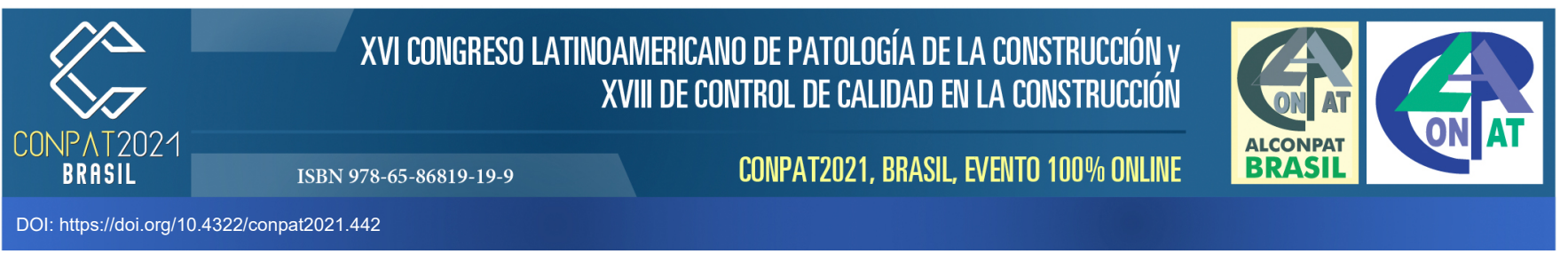

\title{
LEVANTAMENTO E IDENTIFICAÇÃO DE MANIFESTAÇÕES PATOLÓGICAS EM UM SISTEMA ESTRUTURAL METÁLICO: ESTUDO DE CASO DE UMA BENFEITORIA MILITAR NA CIDADE DE SANTIAGO/RS
}

\author{
T. Fanton ${ }^{1 *}$, J. Hardt ${ }^{1}$, E. Saragozo ${ }^{1}$, R. C. A. de Lima ${ }^{1}$, O. R. S. Almeida ${ }^{2}$, E. D. Balbi ${ }^{3}$ \\ *Autor de Contato: tassiafanton@gmail.com \\ ${ }^{1}$ Programa de Pós Graduação em Engenharia Civil, Centro de Tecnologia, Universidade Federal de Santa Maria, \\ Santa Maria/RS, Brasil \\ ${ }^{2}$ Comando da $11^{\text {a }}$ Brigada de Cavalaria Mecanizada, Santiago/RS, Brasil \\ ${ }^{3} 9^{\circ}$ Batalhão Logístico, Santiago/RS, Brasil
}

\begin{abstract}
RESUMO
O aço é um sistema estrutural pouco difundindo na indústria da construção civil brasileira, haja vista que o principal modelo estrutural adotado é o concreto armado. Surge, então, a necessidade da divulgação de aspectos construtivos do aço, bem como dos problemas típicos que acometem esse sistema estrutural. O objetivo dessa pesquisa é apresentar um estudo de caso de uma edificação com estrutura metálica inserida em um aquartelamento na cidade de Santiago/RS. Foram analisadas as manifestações patológicas presentes na estrutura por meio de inspeção visual, ensaio de carbonatação e termografía. Concluiu-se que a degradação da estrutura, caracterizada pela corrosão dos elementos, ocorreu principalmente por conta da falta de proteção do aço, uso de argamassa à base de cal e a presença de umidade ascendente.
\end{abstract}

Palavras chave: Manifestações patológicas; estruturas metálicas; corrosão.

\section{INTRODUÇÃO}


Uma edificação deve oferecer condições de uso, segurança e conforto de forma que as atividades ali desenvolvidas não sofram interferências do meio em que está inserida. Qualquer situação anormal que venha ocorrer com a edificação pode causar prejuízos.

Por conta disso, é eficaz construir com qualidade, com programação de manutenção do que economizar na construção em detrimento da qualidade, implicando em futuros gastos com recuperação da estrutura. (CASTRO, 1999).

Os gastos com recuperação crescem em progressão geométrica à medida que se posterga a tomada de decisões, ou seja, para conseguir a mesma qualidade e durabilidade gastam-se 5 vezes mais à medida que a tomada de decisões é postergada. A "Lei dos 5" ou regra de Sitter, apresentada na Figura 1, demostra o explanado anteriormente.

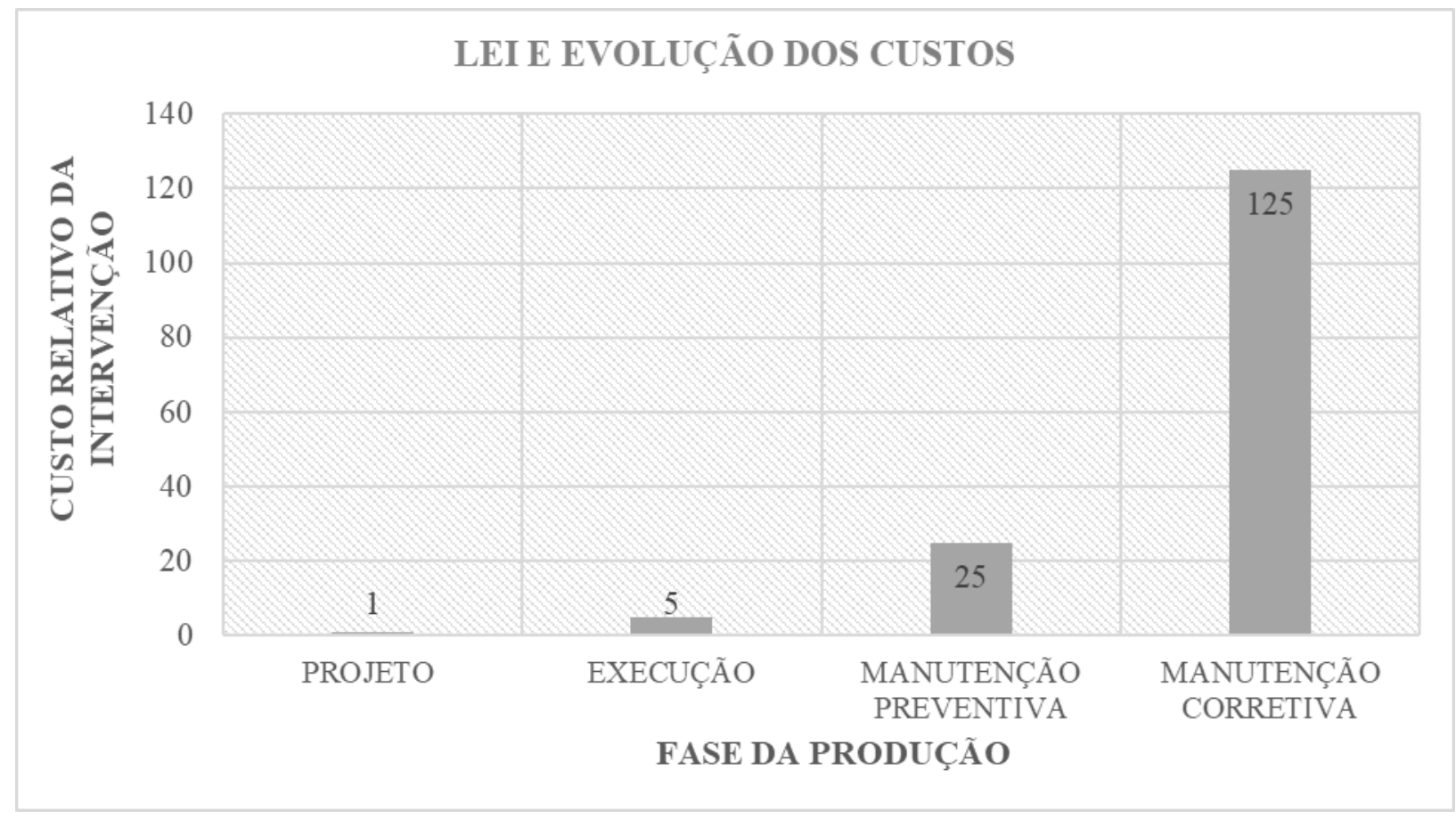

Figura 1. "Lei dos 5" ou Regra de Sitter. Fonte: Helene (1997)

De acordo com o Centro Brasileiro da Construção em Aço (CBCA), atualmente o maior mercado para o aço dentro da construção civil se encontra na execução das obras de energia (eólica, solar e torres de transmissão) e edificações industriais. Isso se dá principalmente devido as suas características de estética, industrialização, rapidez e em alguns casos a sua elevada capacidade de carga. Além disso, uma grande vantagem do uso de estruturas metálicas é a redução dos prazos de execução (CBCA, 2020).

A pesquisa "Cenário dos Fabricantes de Estruturas de Aço" aponta que, desde 2014, esse mercado vem sofrendo com sucessivas quedas de produção. Quando realizada uma comparação, por exemplo, da produção de 2014 (pico) com a de 2018 observa-se uma redução de mais de 50\%. Entretanto, em 2019, houve recuperação de 25,6\%, em relação a 2018 (CBCA, 2020).

Ainda de acordo com o CBCA (2020), os principais gargalos para o fortalecimento e desenvolvimento do setor da construção industrializada em aço no Brasil são a falta de capital de giro, dificuldade de acesso à crédito e os custos tributários que também foram considerados como impactante de forma negativa para o setor. Além disso, o CBCA (2020), cita que há necessidade de maior capacitação do setor da construção civil, ou seja, treinamento da mão de obra para atender ao crescimento da construção industrializada, a qual proporciona redução de prazos e custo. 
No entanto, embora haja tecnologia disponível para resolver os problemas que aparecem nas construções de aço, há um caminho bastante sinuoso para se adquirir o conhecimento necessário para trabalhar com esse material, sendo este um dos maiores entraves quando o assunto é estruturas metálicas. Cita-se o fato de que existe uma dificuldade muito grande dos construtores em se trabalhar com esse sistema, pois utilizam da mesma sistemática construtiva do concreto para o aço. O sistema estrutural do tipo metálico possui uma metodologia própria e não ter conhecimento disso implica em adotar uma solução que pode ser incompatível com o sistema estrutural. Deste modo, os problemas podem surgir e a estrutura metálica acaba adquirindo uma imagem negativa por um problema que não está diretamente vinculado a ela (CASTRO, 1999).

Tendo isso em mente, a presente pesquisa objetiva expor um panorama geral das patologias mais comuns nos sistemas estruturados em aço, bem como apresentar um estudo de caso referente ao sistema estrutural metálico de uma edificação presente em um aquartelamento na cidade de Santiago/RS.

\section{PRINCIPAIS MANIFESTAÇÕES PATOLÓGICAS EM ESTRUTURAS METÁLICAS}

Segundo Pravia e Betinelli (2016), as manifestações patológicas nas estruturas de aço têm suas fontes de anomalias definidas em seis tipos, conforme Figura 2.

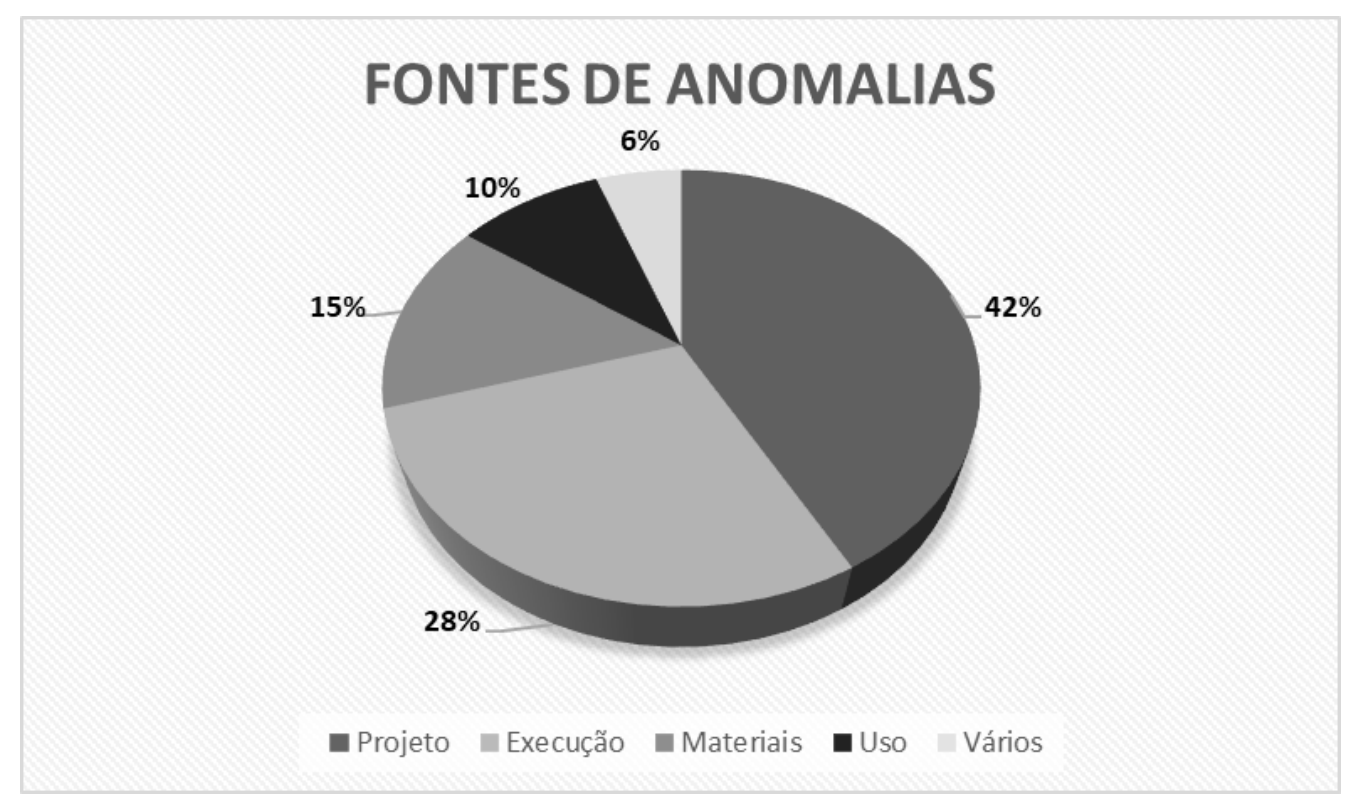

Figura 2. Principais causas das manifestações patológicas. Fonte: Pravia e Betinelli (2016)

No que tange as falhas de projeto e execução, é valido explanar que a vida útil de uma estrutura nasce no projeto e se consolida na execução, mas os conceitos do projeto devem chegar até a conclusão da execução. Além disso, é de extrema importância a integração entre as áreas de projeto, fabricação e montagem. São nessas etapas que deverão ser discutidas as soluções de projetos e as características das peças fabricadas, de tal modo a se evitar na montagem a não disponibilidade de equipamentos, custo excessivo, incompatibilidade da sequência construtiva, alteração no esquema estático e falta de segurança do trabalho. (RAAD JÚNIOR, 1999).

Ainda, para se evitar danos maiores nas estruturas metálicas, torna-se necessária a implantação de manutenções preventivas ou corretivas, as quais deverão ser executadas frequentemente, por 
profissionais com experiência neste tipo de avaliação e inspeções. Deste modo, a partir da utilização de ensaios destrutivos e não destrutivos, será possível avaliar a integridade e o atual estado de uso das edificações em estruturas metálicas, propondo, então, as terapias necessárias para garantir uma maior vida útil ao sistema analisado. É válido destacar que em estudos realizados pelo Instituto Brasileiro de Avaliações e Perícias de Engenharia de São Paulo (IBAPE, 2016), foi verificado que mais de $60 \%$ dos acidentes ocorridos em edifícios com mais de 10 anos estão relacionados à deficiência ou inexistência de manutenção, perda precoce de desempenho e degradação acentuada, destacando ainda mais a importância da existência de um plano de manutenção para as edificações.

No que se refere as principais manifestações patológicas existentes nos sistemas estruturados em aço são apresentadas na Tabela 1 as principais manifestações patológicas, bem como referenciadas as principais causas da sua ocorrência.

Tabela 01 - Principais manifestações patológicas nas estruturas de aço e suas causas. Fonte: Pravia e Betinelli (2016)

\begin{tabular}{|c|c|}
\hline Manifestações patológicas no aço & \multicolumn{1}{c|}{ Principais causas } \\
\hline Corrosão localizada & $\begin{array}{c}\text { Causas por deficiência de drenagem das águas e } \\
\text { deficiências de detalhes construtivos, permitindo o acúmulo } \\
\text { de umidade e de agentes agressivos. }\end{array}$ \\
\hline Corrosão generalizada & $\begin{array}{c}\text { Causada pela ausência de proteção contra o processo de } \\
\text { corrosão. }\end{array}$ \\
\hline Deformações excessivas & $\begin{array}{c}\text { Causadas por sobrecargas ou efeitos térmicos não } \\
\text { previstos no projeto original, ou ainda, deficiências na } \\
\text { disposição de travejamentos. }\end{array}$ \\
\hline Frambagem local ou global & $\begin{array}{c}\text { Causadas pelo uso de modelos estruturais incorretos para } \\
\text { verificação da estabilidade, ou deficiências no enrijecimento } \\
\text { local de chapas, ou efeitos de imperfeições geométricas não } \\
\text { consideradas no projeto e cálculo. }\end{array}$ \\
\hline $\begin{array}{c}\text { Falhas estas iniciadas por concentração de tensões, devido } \\
\text { a detalhes de projeto inadequados, defeitos de solda, ou } \\
\text { variações de tensão não previstas no projeto. }\end{array}$ \\
\hline
\end{tabular}

No que diz respeito a corrosão pode-se dizer que é um tipo de deterioração que pode ser facilmente encontrada em obras metálicas e se caracteriza como um fenômeno patológico de maior conhecimento público. O aço oxida quando em contato com gases nocivos ou umidade, necessitando por isso de cuidados para prolongar sua durabilidade. A perda da seção transversal dos elementos estruturais é o principal problema causado pela corrosão. Esta perda pode aumentar a concentração de tensões (por diminuição da área efetiva) reduzindo consequentemente a capacidade de resistência, e em casos extremos, podendo até provocar a ruína (RAMANATHAN, 1990).

Ainda, é impossível se falar em corrosão sem analisar também os revestimentos orgânicos que são utilizados para a proteção das estruturas metálicas. Verifica-se que estes, como qualquer outro componente de uma edificação, também estão suscetíveis à ação das intempéries e também sofrem 
processos de deterioração, que podem ser acelerados ou não de acordo com o tipo de tinta empregado e as condições ambientais (RAMANATHAN, 1990).

Durante a vida útil do revestimento, depois de algum tempo, o eletrólito tende a alcançar a superfície metálica devido à porosidade natural da película, dando início ao processo corrosivo. Portanto a falha do revestimento se dará sempre por corrosão embaixo da película, exceto nos casos em que haja proteção catódica ou danos por ação mecânica, de forma que a película de tinta seja inicialmente atacada ou danificada antes do comprometimento do aço (RAMANATHAN, 1990).

\section{ESTUDO DE CASO}

A edificação analisada está inserida no aquartelamento do $9^{\circ}$ Batalhão Logístico, localizado na cidade de Santiago/RS, Brasil. O aquartelamento possuí uma área de terreno de $300.000 \mathrm{~m}^{2}$, sendo que a área construída no aquartelamento somando as benfeitorias administrativas e operacionais, esportivas e o Próprio Nacional Residencial (PNR) totaliza aproximadamente $52.700 \mathrm{~m}^{2}$. A edificação alvo desse estudo é destacada na Figura 3 e possui uma área de aproximadamente 600 $\mathrm{m}^{2}$.

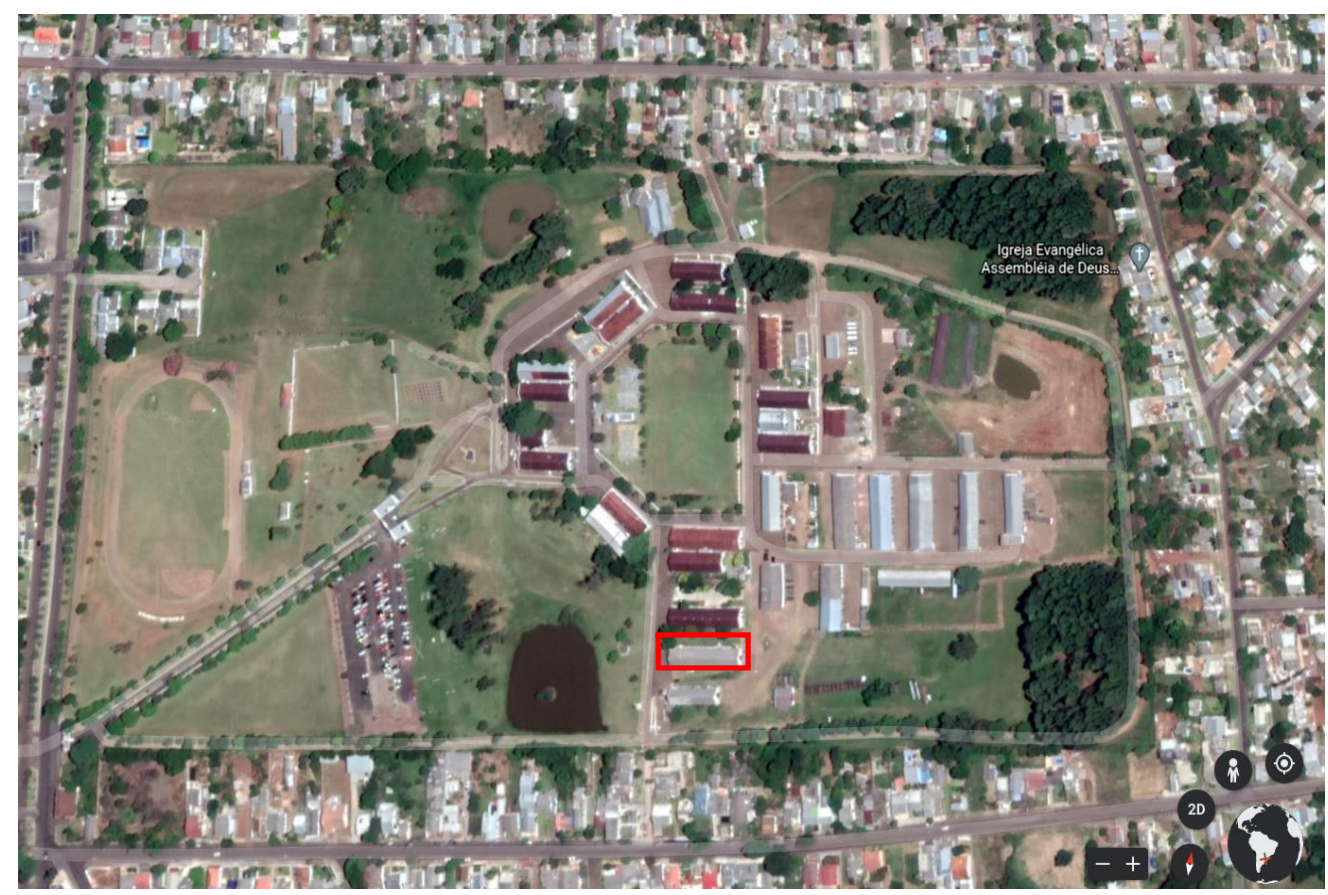

Figura 3. Localização da edificação alvo do estudo

Em relação a época da construção foi verificado nos registros do aquartelamento que a benfeitoria teve sua construção iniciada em 1922, no entanto, no ano de 1924 a obra foi paralisada, sendo então retomada em 1928, ano em que a construção da edificação foi finalizada. Os sistemas construtivos utilizados são: estrutura em aço, vedação em alvenaria de tijolo maciço e revestimento argamassado com pintura. É válido salientar que foi possível verificar na vistoria in-loco algumas adequações na benfeitoria analisada, porém, não foram encontrados registros e documentação no que diz respeito a isso. Na Figura 4 é possível se ter um panorama atual da edificação. 


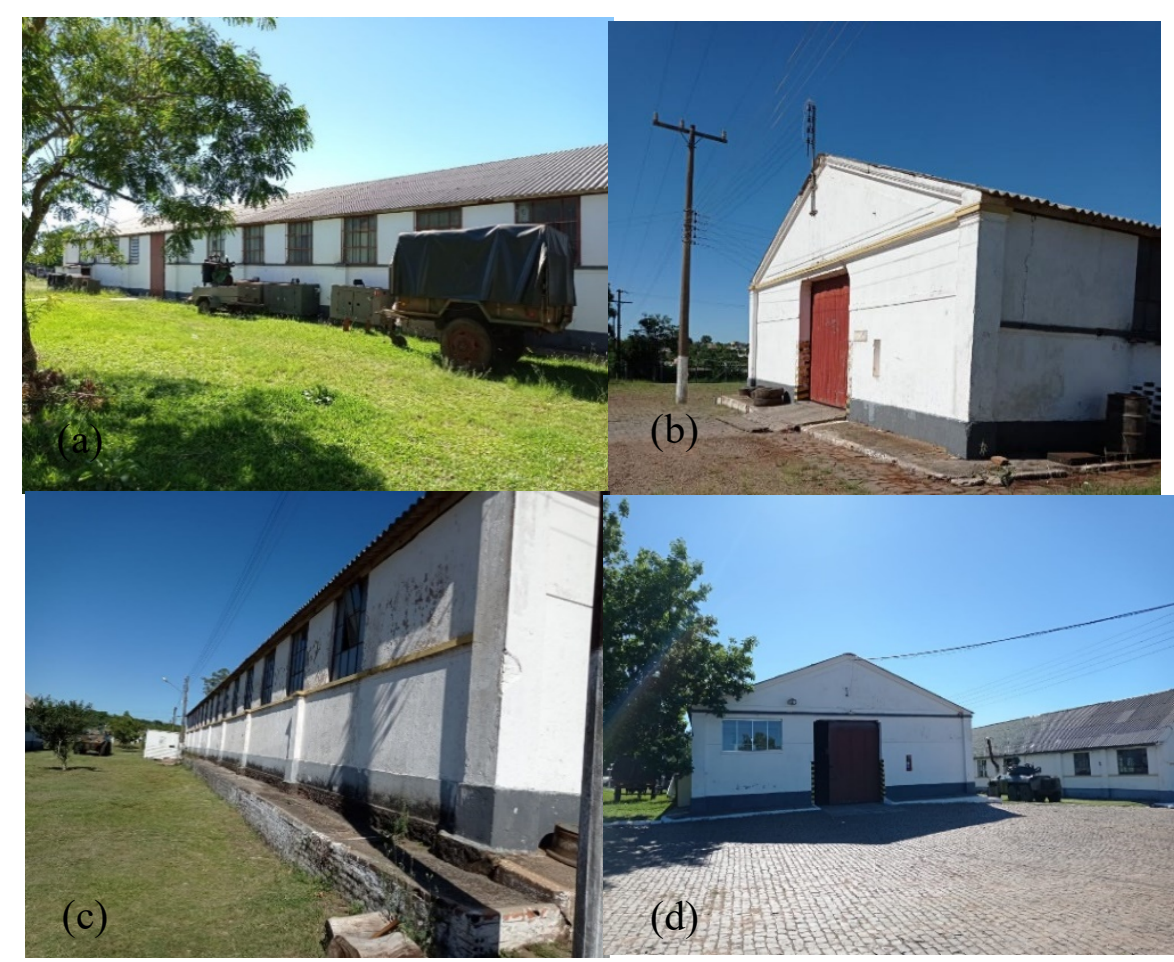

Figura 4. Panorama atual da edificação. (a) Fachada Norte. (b) Fachada Leste. (c) Fachada Sul. (d) Fachada Oeste

Os elementos estruturais alvo desse estudo são os pilares metálicos da edificação, denominados na planta apresentada na Figura 5 de PMXY. Porém, devida a dificuldade de acesso ou pelo fato desses elementos estruturais estarem localizados em áreas de acesso restrito militar, ou seja áreas sensíveis, realizou-se a análise somente dos pilares metálicos destacados em planta na cor rosa.

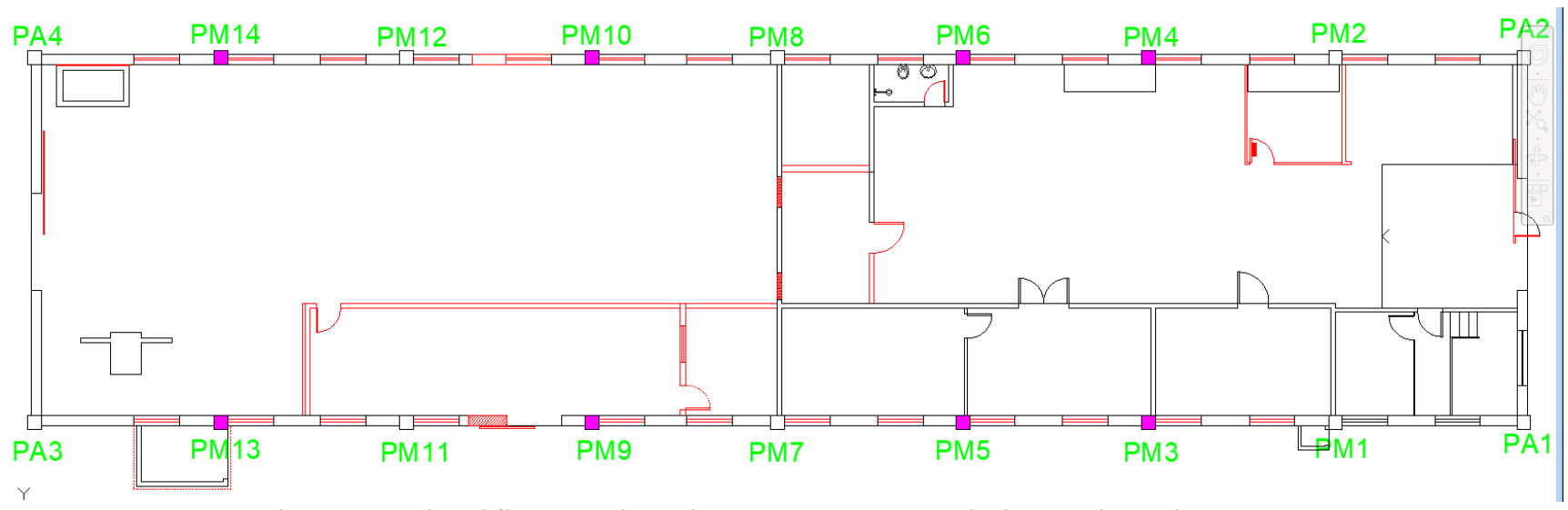

Figura 5. Identificação dos elementos estruturais inspecionados.

Os perfis utilizados para compor o sistema estrutural são do tipo $\mathrm{W}$, com fixação parafusada tanto no topo quanto na base. Na Figura 6 é apresentada a configuração geométrica da seção transversal do perfil, já na Figura 7 a configuração do perfil e o sistema de ligação do topo e da base. 


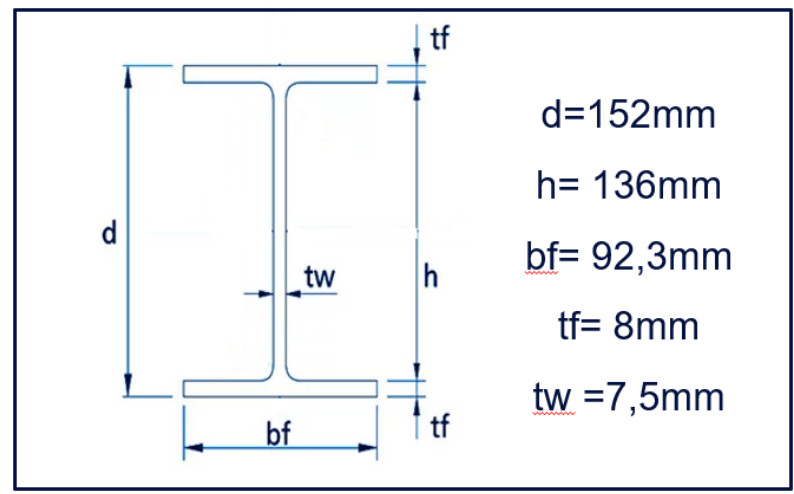

Figura 6. Geometria da seção transversal do perfil

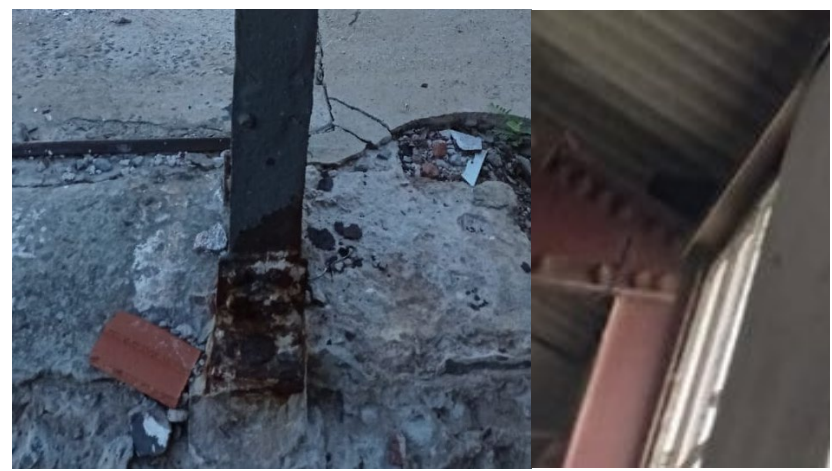

Figura 7. Configuração do perfil e sistema de fixação da base e do topo

Devido à dificuldade de acesso ou de estarem localizados em áreas sensíveis da edificação nem todos os elementos foram inspecionados. Deste modo, o estudo baseou-se nas observações realizadas nos pilares PM3, PM4, PM5, PM6, PM9, PM10, PM13 e PM14. Nesse primeiro momento foram analisadas as seguintes questões: existência de fissura no revestimento argamassado proveniente do processo expansivo de corrosão, aderência do revestimento argamassado, carbonatação do revestimento argamassado, verificação de proteção nos perfis metálicos e altura do processo corrosivo no perfil. Além disso, foram coletadas amostras de argamassa para a futura realização do ensaio de reconstituição de traço. As questões analisadas para cada elemento estrutural são apresentadas na Tabela 02.

Tabela 01 - Inspeção dos elementos estruturais analisados

\begin{tabular}{|c|c|c|c|}
\hline \multicolumn{1}{|c|}{ PM3 } \\
\hline $\begin{array}{c}\text { Fissuração no } \\
\text { revestimento, } \\
\text { proveniente das } \\
\text { reações } \\
\text { expansivas do } \\
\text { processo } \\
\text { corrosivo. }\end{array}$ & & $\begin{array}{c}\text { Perfil metálico sem } \\
\text { proteção (pintura). } \\
\text { Processo corrosivo } \\
\text { acentuado até } \\
1,35 \text { m do perfil em } \\
\text { relação ao solo }\end{array}$ \\
\hline
\end{tabular}




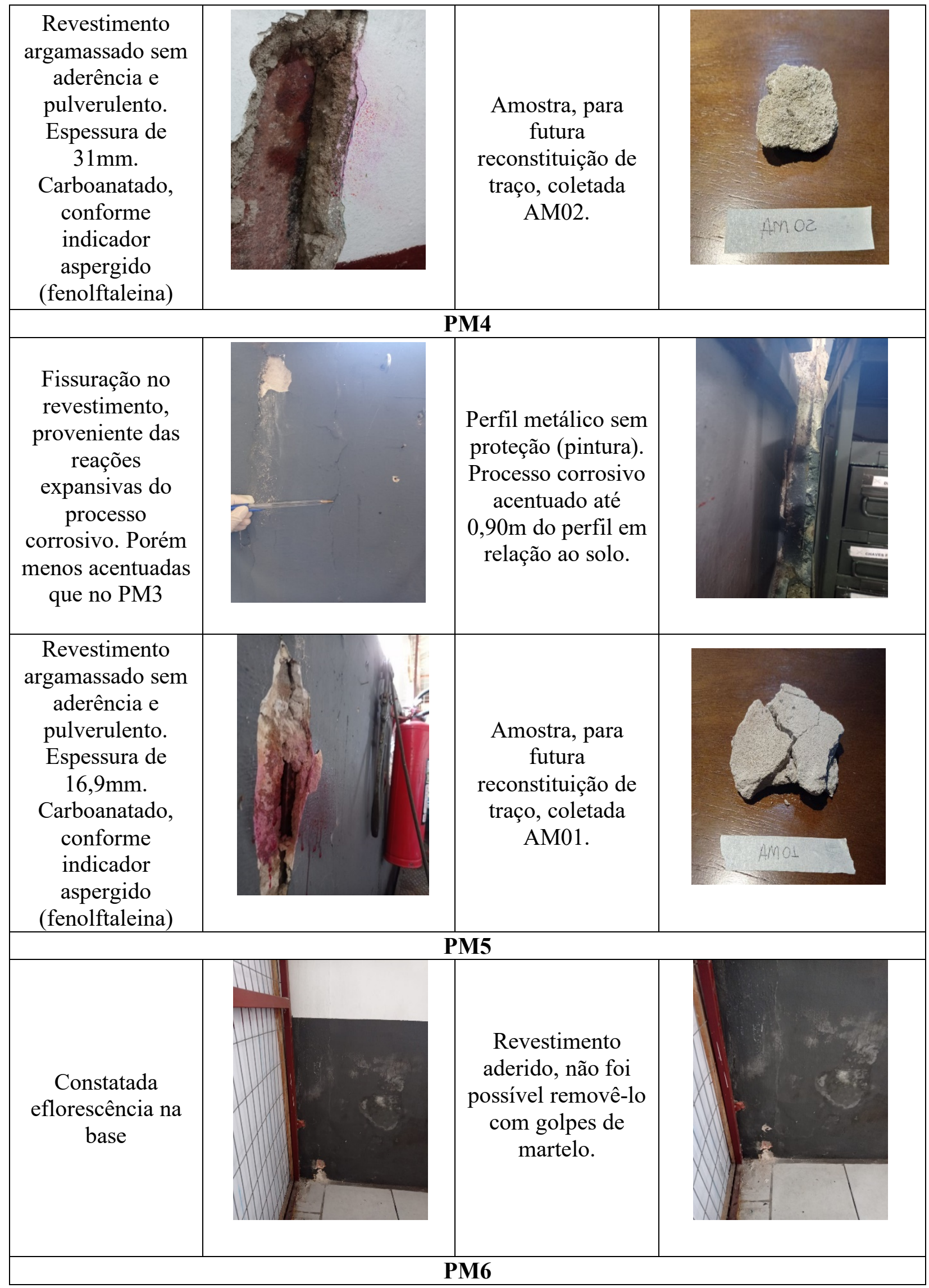




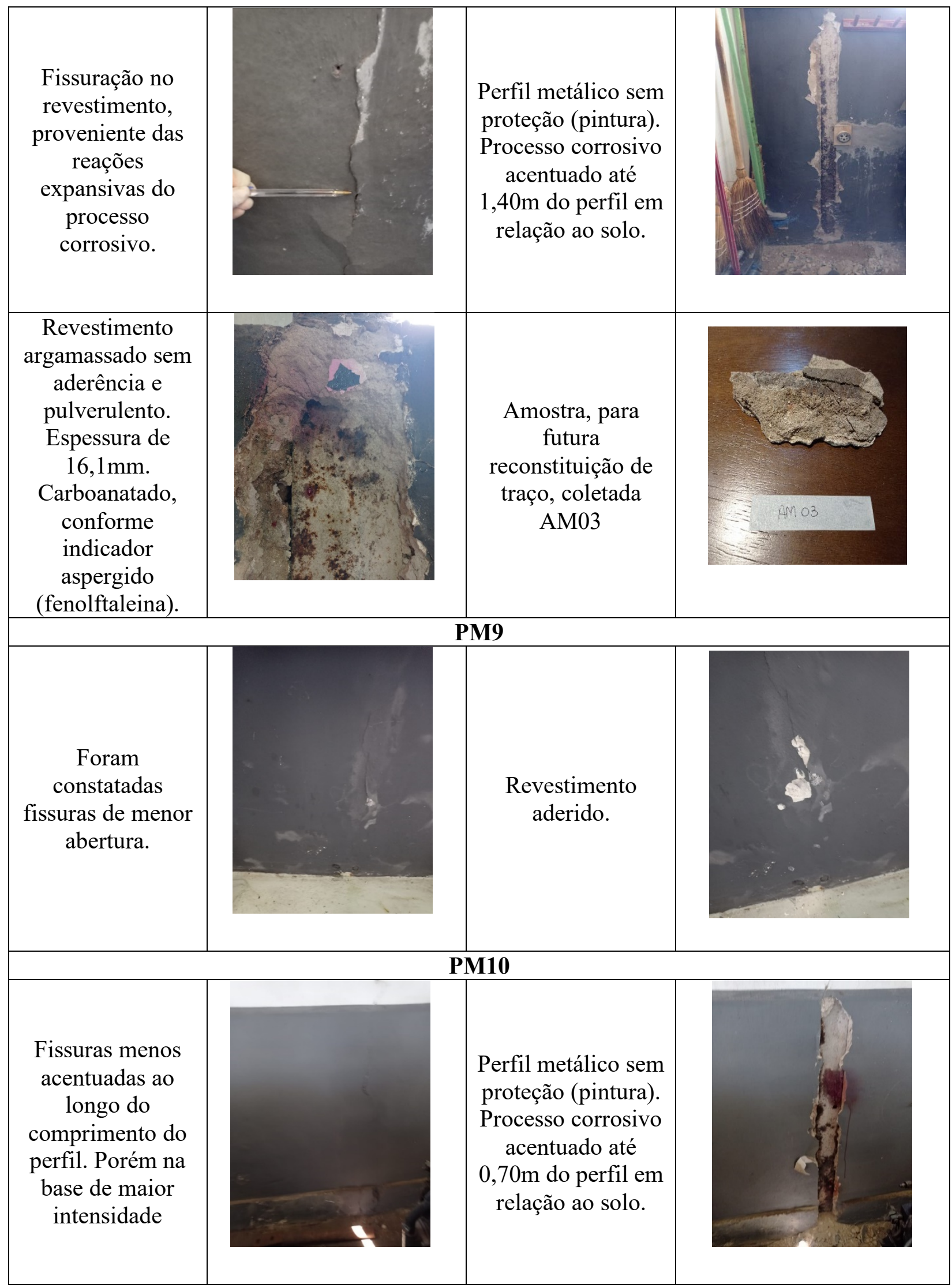




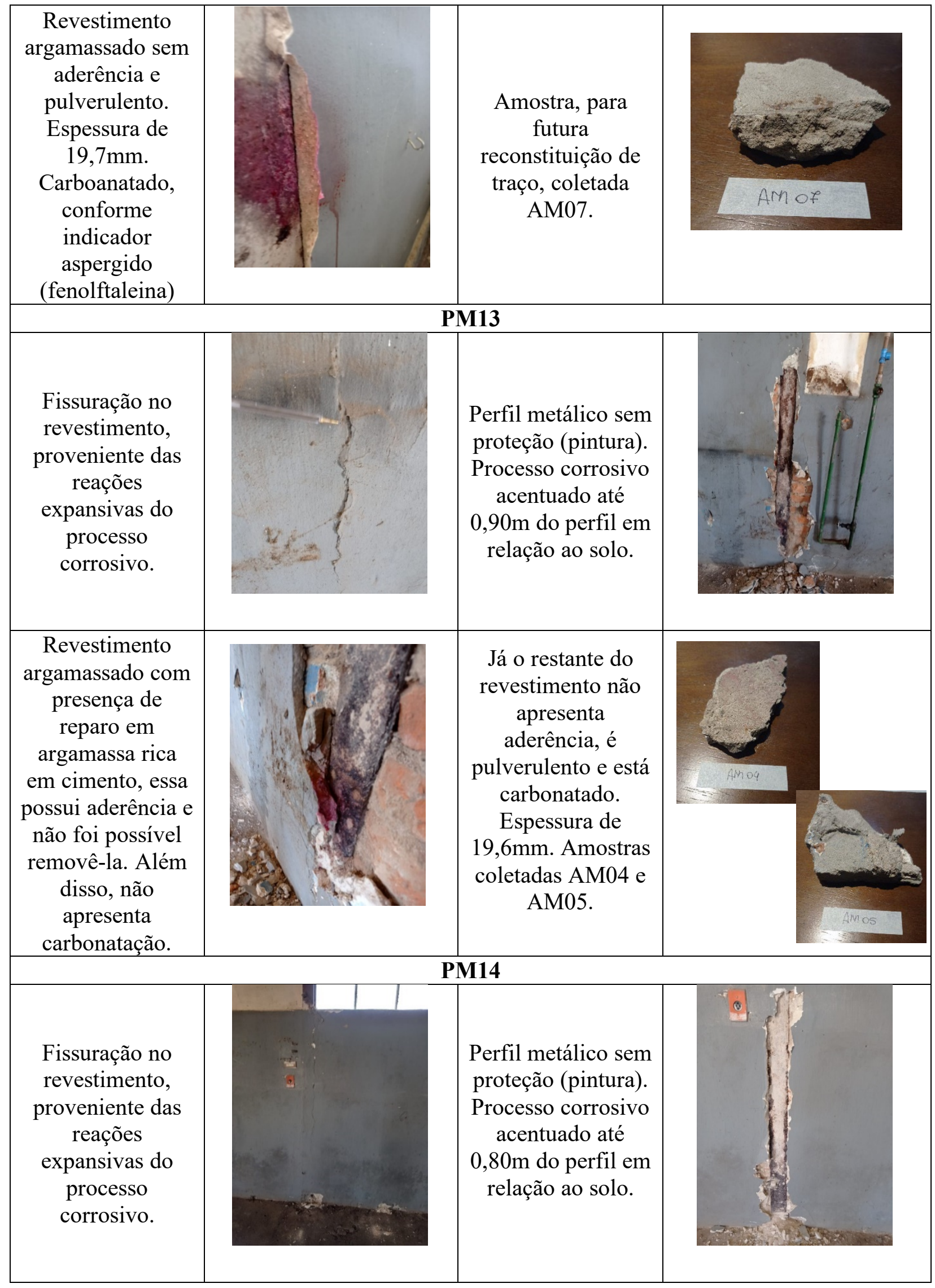




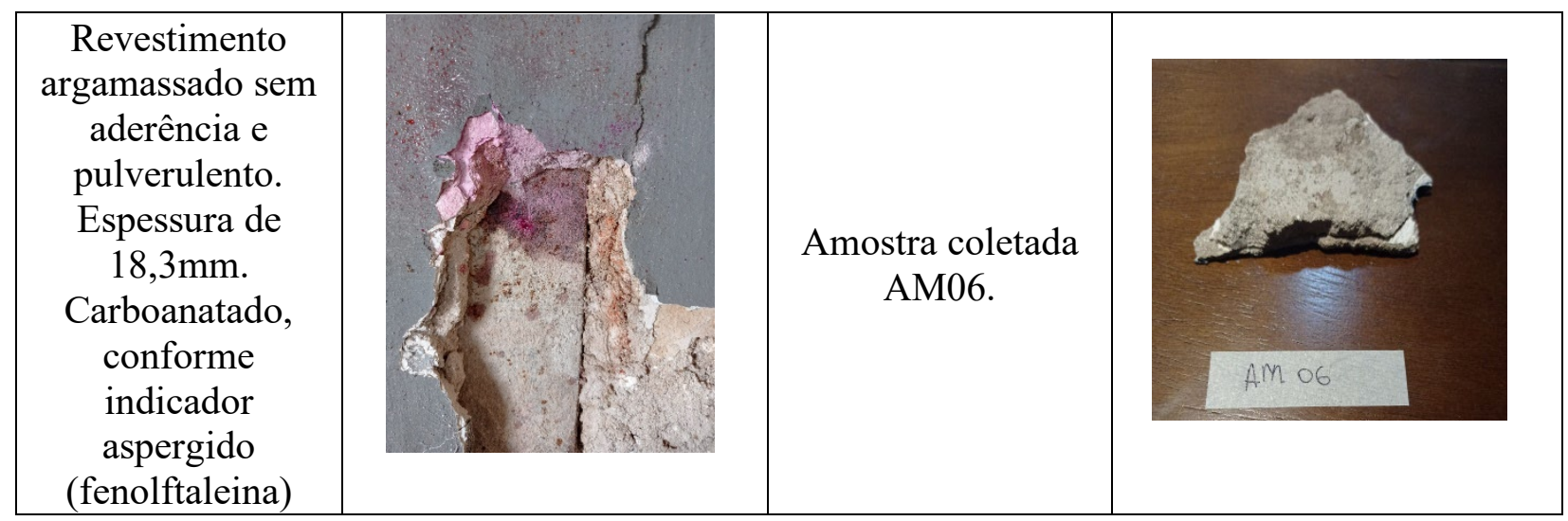

Afim de complementar o apresentado na Tabela 01, foi realizada uma análise termográfica no pilar PM6, o equipamento utilizado foi o FLIR E53 Model: 84502-0201, Na Figura 8 é apresentada a termografia do elemento analisado.

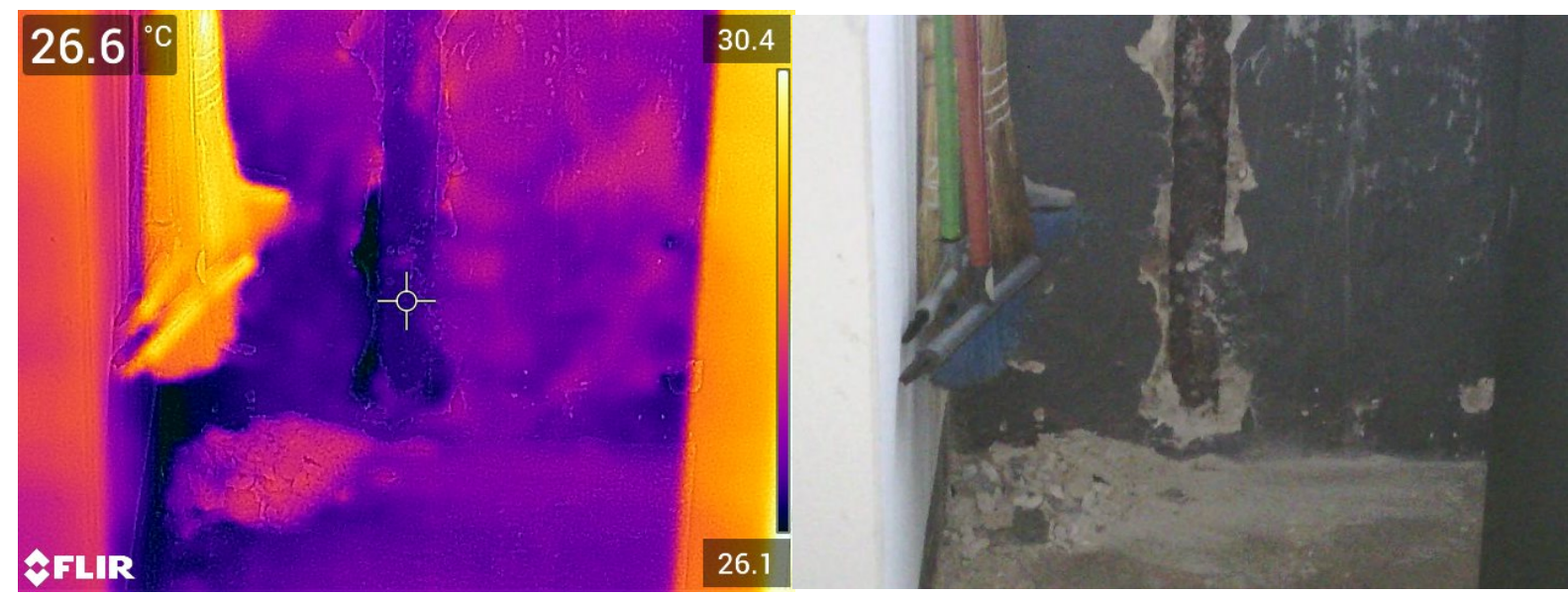

Figura 8. Imagem termográfica perfil PM6

Destaca-se que é perceptível na Figura 8 a existência de um gradiente de temperatura, sendo verificado na parte inferior da região analisada, bem como na união das paredes adjacentes os menores valores de temperatura. É valido expor que a parede adjacente a região analisada delimita uma instalação sanitária presente na edificação, ou seja, é uma área suscetível a presença de umidade. Deste modo por meio da imagem supracitada e partir da verificação das menores temperaturas na região inferior e adjacente a parede do sanitário, pode-se verificar a presença de umidade nesse local. Salienta-se que a presença de umidade favorece a formação de eletrólitos nas superfícies metálicas e consequentemente da corrosão, por conta disso a umidade acescente presente e a falta de um revestimento adequado na instalação sanitária presente na edificação favoreceram o processo corrosivo encontrado na estrutura metálica.

\section{ANÁLISE E DISCUSSÃO}

Tendo como base o apresentado na Tabela 01 pode-se constatar que a altura de corrosão nos elementos estruturais analisados é de $1,35 \mathrm{~m}$ para PM3; 0,90m para PM4; 1,40 para PM6; 0,70 para PM10; 0,90 para PM13 e 0,80 para PM14, o que resulta em uma altura média de 1,00m. Ainda, pode-se verificar que o revestimento argamassado não apresentou aderência, a partir da aplicação de golpes de martelo, nos perfis analisados com exceção dos elementos PM5 e PM9. No que diz 
respeito aos pilares PM5 e PM9 é interessante destacar que ambos elementos estão situados na fachada norte da edificação, ou seja, estão expostos a uma maior incidência solar quando comparados aos elementos localizados na fachada sul, assim, estão sujeitos a uma menor exposição à umidade. No que se refere a proteção dos perfis metálicos, não foi observada a aplicação de uma película de proteção ou qualquer outro sistema, salienta-se que para que o processo corrosivo ocorra é necessário a existência do contato direto entre o meio corrosivo (eletrólito) e o aço, assim, com a aplicação de uma película/revestimento protetor o contato entre o eletrólito e o metal deixa de existir, desta forma, a película de proteção constituí uma barreira física que impede a ocorrência das reações catódicas, compondo um mecanismo de proteção.

Em relação à argamassa utilizada no revestimento, a qual estava em contato direto com os perfis metálicos, verificou-se que essa além de sinalizar o processo expansivo de corrosão por meio de fissuras a mesma apresentou sinais de carbonatação, conforme indicação por aspersão de fenolftaleína. Tendo isso em vista, provavelmente a argamassa teve cal adicionada na sua composição o que favoreceu o processo de oxidação dos perfis, o favorecimento à degradação deve-se ao fato de que a reação do hidróxido de cálcio com anidrido carbônico resulta em carbonato de cálcio, o qual possui um $\mathrm{pH}$ inferior ao hidróxido de cálcio, com isso há uma diminuição do $\mathrm{pH}$ do revestimento argamassado o qual provoca a despassivação do aço. No que tange a carbonatação verificou-se que somente para o pilar PM13 parte do revestimento argamassado não se apresentava carbonatado, porém, pela análise realizada verificou-se a existência de um reparo no revestimento o qual, provavelmente, foi executado em uma época posterior ao revestimento geral da edificação com uma argamassa rica em cimento, haja vista a coloração da Amostra 05 coletada.

Além disso, destaca-se que os pilares que apresentaram, por meio de inspeção visual, maior índice de corrosão foram os pilares PM3 e PM6, esse último foi submetido a análise temográfica. Em relação a esses elementos estruturais evidencia-se que o perfil PM3 está localizado na fachada norte, porém, há a existência de uma árvore a qual projeta sombra nessa área da edificação, além disso, há a existência de uma lareira ao lado do elemento estrutural, a qual pode ter acelerado o processo de carbonatação por conta da emissão de dióxido de carbono $\left(\mathrm{CO}_{2}\right)$.

\section{CONCLUSÕES}

Foram verificados indicativos de expansão por processo corrosivo no revestimento argamassado por meio de fissuras. Ainda se verificou que todos os pilares, em que foi possível remover o revestimento argamassado, não apresentavam proteção. Também o revestimento se apresentava carbonatado, exceto em parte do pilar PM13, é válido salientar que as análises se deram no lado interno da edificação, uma vez que os pilares estão envoltos por alvenaria no lado externo. A corrosão encontrada é mais acentuada na base dos perfis, sendo essa até a altura média de 1,0m. No que tange a maior degradação por meio visual destaca-se à encontrada nos pilares PM3 e PM6, sendo que no pilar PM3 é projetada a sombra de uma árvore existente além desse estar localizado em um cômodo da edificação que possuí uma lareira, a qual pode ter acentuado a emissão de $\mathrm{CO}_{2}$ e acelerado o processo de carbonatação. Já o pilar PM6 fica localizado na fachada sul e está localizado ao lado de um sanitário, então, a umidade pode ter sido determinante para a sua degradação.

Deste modo, evidencia-se que a patologia predominante no sistema é a corrosão dos elementos estruturais dentre as causas estão a falta de proteção do perfil metálico, seguido da aplicação de um revestimento argamassado com cal, haja vista a constatação da carbonatação e acentuados pela umidade ascendente.

No entanto, é válido destacar que, de acordo com os registros do aquartelamento, a estrutura analisada possuí cerca de 99 anos, ou seja, tendo em vista não há registros da realização de manutenções preventivas ou corretivas na estrutura a mesma cumpriu com seu tempo de vida útil, 
o qual de acordo com a NBR 15575:2013 é de no mínimo 50 anos para os sistemas estruturais. Porém, caso as manutenções preventivas tivessem sido realizadas a intervenção para a recuperação do sistema estrutural no atual momento provavelmente seria menos onerosa.

Como próxima etapa desta pesquisa, tem-se como intuito analisar a composição do revestimento argamassado utilizado na edificação afim de verificar a composição do traço utilizado, evidenciando a quantidade de cal utilizada, bem como disponibilizar as informações aqui coletadas e auxiliar no projeto contratado pela Organização Militar para a recuperação estrutural da edificação.

\section{REFERÊNCIAS}

Castro, Eduardo M. C. de. (1999), "Patologia dos edifícios em estrutura metálica”. Universidade Federal de Ouro Preto, p. 202.

Centro Brasileiro da Construção em Aço (2020). "Relatório de Atividades". Rio de Janeiro, p. 40. Disponível em: < www.cbca-acobrasil.org.br>. Acesso em 15 jan. 2021.

Henriques, F. M. A. (2001), "Noção de Qualidade em Edifícios". Comunicação ao Congresso Nacional da Construção. Lisboa.

Instituto Brasileiro de Avaliações e Perícias de Engenharia. (2016), "Inspeção Predial, a saúde dos Edifícios”. São Paulo, p. 27. Disponível em: <https://ibape-sp.org.br>. Acesso em 15 jan. 2021.

Nunes, Laércio de Paula. LOBO, Alfredo Carlos O. (1990), "Pintura industrial na proteção anticorrosiva". Rio de Janeiro: Livros técnicos e científicos editora, p. 250.

Pravia, Z. M. C.; Betinelli, E. A. (2016), "Falhas em estruturas metálicas: Conceitos e estudos de caso". Curso de Engenharia Civil da FEAR -UPF. Disponível em: <www.metalica.com.br>. Acesso em 15 jan. 2021.

Raad Júnior, Antonnie Aziz. (1999), "Diretrizes para fabricação e montagem das estruturas metálicas”. Dissertação de Mestrado. Ouro Preto: Universidade Federal de Ouro Preto, p. 218.

Ramanathan, Lalgudi V. (1990), "Corrosão e seu controle”. 1. ed. São Paulo: Hemus editora ltda, p. 342 .

Sacchi, Caio César. (2016), “Avaliação de desempenho estrutural e manifestações patológicas em estruturas metálicas”. São Carlos: UFSCar, p. 137. 